\title{
Raccoon rabies outbreak in Hamilton, Ontario: A progress report
}

\author{
D Lobo ${ }^{1 *}$, C DeBenedet ${ }^{2}$, C Fehlner-Gardiner ${ }^{3}$, SA Nadin-Davis ${ }^{3}$, MEC Anderson ${ }^{4}$, T Buchanan $^{5}, \mathrm{~K}$ \\ Middel $^{5}$, C Filejski ${ }^{6}$, J Hopkins ${ }^{7,8 *}$
}

\begin{abstract}
Background: Raccoon rabies is caused by a variant of the rabies virus found in raccoons but transmissible to other mammalian species, including humans. The disease of rabies caused by raccoon variant rabies virus is indistinguishable from rabies caused by other rabies virus variants.
\end{abstract}

Objective: This paper describes the raccoon rabies outbreak in Ontario (identified in December 2015) and the control measures undertaken to curb the spread of the epizootic using the One Health approach.

Investigation and Results: Representatives from local, provincial and federal agencies collectively activated a raccoon rabies response that involved policy updates, enhanced surveillance, a public education campaign and mass vaccination of wildlife and domestic animals. Between December 2015 and June 2017, 338 animals tested positive for raccoon rabies in Ontario. While the majority of the cases were raccoons, there was significant spillover into striped skunks, as well as other species including two cats, a fox and a llama. Viral genome sequencing determined that this epizootic was likely caused by long-distance translocation from the United States.

Conclusion: This outbreak of raccoon rabies is by far the largest to have occurred in Canada and the first raccoon rabies outbreak documented in a densely populated urban area. This is also the first time this rabies virus variant has been identified in a domestic animal in Canada. A collaborative approach involving numerous stakeholders in the public and private sectors has been instrumental in addressing this epizootic. Though case incidence appears to be declining, several years will likely be required to reach elimination. Continued collaboration between these agencies is necessary to achieve this goal.

\author{
Affiliations \\ 1 Public Health and Preventive \\ Medicine Residency Program, \\ McMaster University, Hamilton, \\ ON \\ 2 Hamilton Public Health Services, \\ Hamilton, ON \\ ${ }^{3}$ Canadian Food Inspection \\ Agency, Ottawa, ON \\ ${ }^{4}$ Ontario Ministry of Agriculture, \\ Food and Rural Affairs, Guelph, \\ ON \\ ${ }^{5}$ Ministry of Natural Resources \\ and Forestry, Peterborough, ON \\ ${ }^{6}$ Ministry of Health and \\ Long-Term Care, Toronto, ON \\ ${ }^{7}$ Region of Peel, Mississauga, ON \\ ${ }^{8}$ Department of Health Research \\ Methods, Epidemiology, and \\ Impact, McMaster University, \\ Hamilton, ON
}

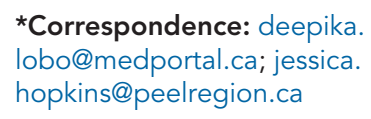

Suggested citation: Lobo D, DeBenedet C, Fehlner-Gardiner C, Nadin-Davis SA, Anderson MEC, Buchanan T, Middel K, Filejski C, Hopkins J. Raccoon rabies outbreak in Hamilton, Ontario: a progress report. Can Commun Dis Rep. 2018;44(5):116-21. https://doi.org/10.14745/ccdr.v44i05a05

Key words: Raccoon rabies, rabies outbreak, One Health approach, genome sequencing

\section{Introduction}

On December 4, 2015, the public health department in Hamilton, Ontario was notified that a locally trapped raccoon had tested positive for the raccoon variant of the rabies virus. The raccoon had been tested because it had been in a fight with two unvaccinated domestic dogs. This was the first case of raccoon rabies in the province since 2005 and the first case of raccoon rabies ever recorded in southwestern Ontario. In the following 19 months, raccoons with rabies were identified in areas surrounding Hamilton including Niagara Region, Brant County, Halton Region and Haldimand-Norfolk.

Rabies virus is a Lyssavirus in the family Rhabdoviridae. It has a high affinity for neural tissue and causes death through encephalomyelitis (1). Viral variants are viral populations that are maintained in specific host reservoirs in a geographic area and are distinct from other viral populations that may be located in the same area or that have diverged from a common viral ancestor (2). The disease caused by the raccoon variant rabies virus is indistinguishable from rabies caused by other variants. In the interest of brevity, for this report "raccoon rabies" is used to mean rabies caused by the raccoon variant rabies virus, whether the disease is present in raccoons or another species.

This article provides an update on the raccoon rabies epizootic in Ontario, particularly in and around Hamilton, Ontario, where the outbreak was first identified in December 2015. It describes the control measures undertaken to curb the spread of the epizootic and the collaborative One Health approach used by the many agencies involved in the response. 


\section{Background}

Raccoon rabies originally emerged in the state of Florida in the 1940s, spreading to the Mid-Atlantic states in the 1970s. It has since spread throughout the eastern seaboard of the United States (US), reaching the Canada-US border in the mid-1990s (3,4). It was first detected in Ontario in 1999 (5) and was localized to two rural areas in eastern Ontario with 132 laboratory-confirmed cases detected over six years. It was successfully eliminated in 2005 with Ontario being declared free of raccoon rabies in September 2007 (6). Incursions of raccoon rabies from neighbouring US states into New Brunswick (2000-2002; 64 cases) and Quebec (2006-2009; 104 cases) were similarly eliminated (6).

The responsibility for rabies control in Canada is shared across multiple jurisdictions and reflects the One Health approach, a concept that recognizes the relationships between public health, animal health and the environment. The One Health approach applies a coordinated, collaborative, multidisciplinary and cross-sectoral effort to address potential or existing risks that originate at the animal-human-ecosystems interface (7). At the federal level, the Canadian Food Inspection Agency (CFIA) provides rabies laboratory testing services for animal and human samples. In Ontario, the Ministry of Health and Long-Term Care (MOHLTC) provides guidance and support for the local management of suspected rabies exposure, local rabies contingency plans and legislation around rabies immunization. Local public health units are responsible for all activities dealing with prevention of rabies cases in humans, including postexposure case management of people potentially exposed to rabies virus, provision of rabies postexposure prophylaxis (rPEP) vaccine to primary care providers, and raising public awareness. The Ontario Ministry of Agriculture, Food and Rural Affairs (OMAFRA) assists veterinarians as needed with risk assessments, sample submission and postexposure management of companion animals and livestock (collectively, domestic animals) potentially exposed to rabies by wildlife or other domestic animals. The Ministry of Natural Resources and Forestry (MNRF) is responsible for rabies control activities in wildlife, which include enhanced surveillance in wildlife populations at risk, testing of samples and mass vaccination programs.

\section{Investigation and Results}

\section{Coordinating a One Health approach}

Following confirmation of the first case of raccoon rabies in Hamilton in December 2015, Hamilton Public Health Services activated a raccoon rabies response based on the MOHLTC raccoon rabies contingency plan, and revised its rabies risk assessment tool to reflect the change in local epidemiology (i.e. a local rabid raccoon). This was followed by updating case management algorithms for potential human exposures and alerting local health care providers to incorporate local epidemiology into postexposure management.

In 2013, Hamilton Public Health Services was one of six health units in Ontario that helped form a community One Health committee. Members of the committee met with local veterinary professionals, animal control services and representatives from other agencies to discuss diseases prevalent in both humans and animals, and share information about various environmental risk factors. As a result, Hamilton Public Health Services had well-established relationships in place before the identification of this epizootic, which helped in the rapid implementation of the raccoon rabies response.

Rabies does not have a direct environmental impact as it is a mammalian virus and very fragile outside of the body. However, it can have a significant impact on wildlife populations (especially the reservoir species - bats, raccoons, skunks, foxes - in which specific rabies virus variants circulate) and therefore the ecosystems in which they live. In this sense, the contributions of public health, OMAFRA and MNRF round out the One Health players in terms of human, animal and environmental health.

Another unique feature of this response was that there was no single "lead" organization; the response was shared with each organization leading the part that was within their mandate. Close collaboration and active communication were essential to coordinate activities and work towards one common overall goal of eliminating raccoon rabies in Ontario.

\section{Animal health response}

\section{Case definition}

A confirmed case of raccoon rabies was defined as an animal testing positive for rabies using the fluorescent antibody test together with virus typing methods utilizing either monoclonal antibody panels or sequencing to identify the raccoon variant. These procedures were carried out by the Centre of Expertise for Rabies at the CFIA. Geographical attribution of positive animals was based on local public health unit boundaries.

\section{Case detection/Surveillance}

Cases were identified through different processes, depending on whether people or domestic animals had been potentially exposed to the suspect animal or the suspect animal was identified through other surveillance activities. The decision to test a suspect animal that had potentially exposed humans to rabies was made by the local public health unit. The decision to test a suspect animal that had potentially exposed domestic animals alone to rabies was made by OMAFRA, typically in collaboration with the exposed animal's veterinarian. In both cases, samples were shipped directly to CFIA for testing.

In December 2015, MNRF implemented enhanced rabies surveillance in an area extending 50 kilometers beyond where all diagnosed cases were found, with weekly testing of sick or found-dead animals with no known human or domestic animal contact, using a direct rapid immunohistochemical test (dRIT) (8). Confirmatory testing on all dRIT-positive and inconclusive samples was performed by CFIA. This enhanced surveillance was used to understand the scope (species and geographic) of spread and number of animals impacted.

Between December 2015 and June 2017, 338 animals tested positive for raccoon rabies in Ontario. Of these, 251 (74\%) were from the area around Hamilton. Five or more animals tested 
positive for raccoon rabies every month between December 2015 and June 2017, with an average of 18 animals per month (range 5-30). In contrast, in 2014 only 18 rabies cases were detected in the entire province, all in bats (9). An epizootic curve for the outbreak is shown in Figure 1.

Figure 1: Epizootic curve showing ongoing raccoon rabies outbreak in Ontario, December 2015 to June 2017

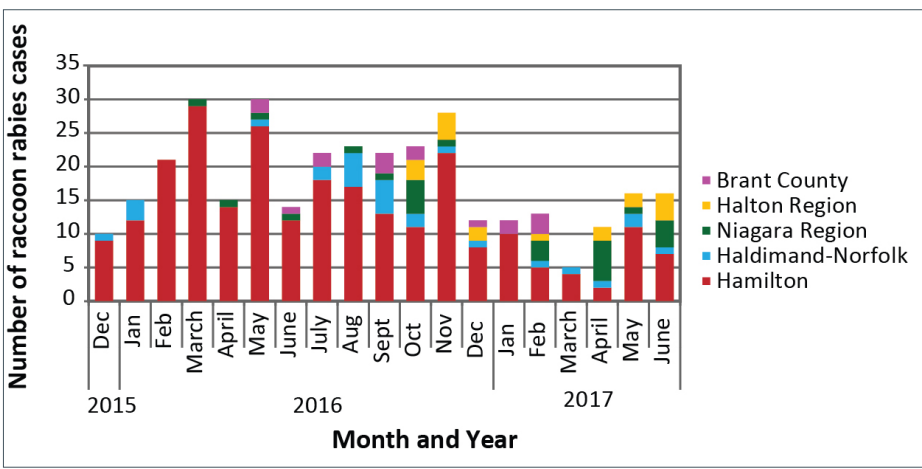

While the rabies outbreak was mostly confined to raccoons, the reservoir species for this virus variant, there was significant cross-species transmission of the raccoon virus ("spillover") into striped skunks, as well as some spillover into other species, including two cats, a red fox and a llama (Table 1).

Table 1: Animal species tested positive for raccoon rabies in Ontario, December 2015 to June 2017

\begin{tabular}{|c|c|c|c|c|c|c|c|}
\hline Year & Animal & $\begin{array}{c}\text { Hamilton } \\
\text { Region }\end{array}$ & $\begin{array}{l}\text { Haldimand- } \\
\text { Norfolk } \\
\text { County }\end{array}$ & $\begin{array}{l}\text { Niagara } \\
\text { Region }\end{array}$ & $\begin{array}{l}\text { Halton } \\
\text { Region }\end{array}$ & $\begin{array}{l}\text { Brant } \\
\text { County }\end{array}$ & TOTAL \\
\hline $\begin{array}{l}2015 \\
\text { (December) }\end{array}$ & Raccoon & 9 & 1 & 0 & 0 & 0 & 10 \\
\hline \multirow{5}{*}{2016} & Raccoon & 126 & 17 & 10 & 7 & 11 & 171 \\
\hline & Skunk & 76 & 1 & 2 & 2 & 0 & 81 \\
\hline & Cat & 0 & 1 & 0 & 0 & 0 & 1 \\
\hline & Fox & 1 & 0 & 0 & 0 & 0 & 1 \\
\hline & Llama & 0 & 1 & 0 & 0 & 0 & 1 \\
\hline \multirow{3}{*}{$\begin{array}{l}2017 \\
\text { (January to } \\
\text { June) }\end{array}$} & Raccoon & 24 & 5 & 12 & 4 & 5 & 50 \\
\hline & Skunk & 14 & 1 & 2 & 5 & 0 & 22 \\
\hline & Cat & 1 & 0 & 0 & 0 & 0 & 1 \\
\hline \multicolumn{2}{|l|}{ TOTAL } & 251 & 27 & 26 & 18 & 16 & 338 \\
\hline
\end{tabular}

Between December 2015 and June 2017, MNRF tested 6,685 animals (wildlife species with no known human or domestic animal exposure) using dRIT. Of these, 326 (4.89\%) were identified by dRIT and confirmed by fluorescent antibody testing and subsequent variant typing as positive for raccoon rabies (Table 2). An additional 12 cases were identified during this time from samples submitted by MOHLTC or OMAFRA.

\section{Source identification}

The source of this outbreak was explored by comparing the whole-genome sequence of two virus isolates from Hamilton with a large database of raccoon variant rabies virus genomes
Table 2: Number of animals tested for rabies using dRIT in Ontario, December 2015 to June 2017

\begin{tabular}{|c|c|c|c|c|}
\hline Year & Month & $\begin{array}{l}\text { Number } \\
\text { of } \\
\text { animals } \\
\text { tested }\end{array}$ & $\begin{array}{l}\text { Number } \\
\text { of animals } \\
\text { confirmed } \\
\text { positive }\end{array}$ & $\begin{array}{c}\text { Proportion } \\
\text { of animals } \\
\text { tested } \\
\text { positive (\%) }\end{array}$ \\
\hline 2015 & Dec & 147 & 12 & 8.2 \\
\hline \multirow[t]{12}{*}{2016} & Jan & 369 & 19 & 5.2 \\
\hline & Feb & 588 & 26 & 4.4 \\
\hline & March & 781 & 19 & 2.4 \\
\hline & April & 627 & 23 & 3.7 \\
\hline & May & 453 & 24 & 5.3 \\
\hline & June & 338 & 16 & 4.7 \\
\hline & July & 274 & 18 & 6.6 \\
\hline & Aug & 304 & 23 & 7.6 \\
\hline & Sept & 228 & 27 & 11.8 \\
\hline & Oct & 247 & 22 & 8.9 \\
\hline & Nov & 255 & 19 & 7.5 \\
\hline & Dec & 123 & 11 & 8.9 \\
\hline \multirow[t]{6}{*}{2017} & Jan & 121 & 12 & 9.9 \\
\hline & Feb & 277 & 13 & 4.7 \\
\hline & March & 310 & 3 & 1.0 \\
\hline & April & 377 & 12 & 3.2 \\
\hline & May & 445 & 16 & 3.6 \\
\hline & June & 421 & 11 & 2.6 \\
\hline Total & --- & 6,685 & 326 & 4.9 \\
\hline
\end{tabular}

Abbreviation: dRIT, direct rapid immunohistochemical test

from across the eastern US. The viruses circulating just across the border in New York state, where raccoon rabies has been endemic since the late 1990s, were phylogenetically very distinct from those responsible for the Hamilton outbreak, supporting the conclusion that this epizootic represents a long-distance translocation into the area (10).

\section{Vaccination}

Animal vaccination was one of the main strategies in minimizing the spread of raccoon rabies, particularly through oral vaccination of raccoons and skunks. Between December 2015 and June 2017, MNRF distributed over 1.7 million baits containing $O N R A B^{\circledR}$ (live adenovirus vector $A d R G$ 1.3) oral rabies vaccine during campaigns in December 2015, spring 2016 and fall 2016. The baits were distributed by hand in urban areas, by helicopter in large urban green spaces and by fixed-wing aircraft in surrounding rural areas across the enhanced surveillance area.

In addition, Hamilton Public Health Services in conjunction with local veterinarians held two rabies vaccination clinics for domestic cats and dogs in September 2016 and April 2017. These clinics were organized to provide rabies vaccination at a lower cost, enabling lower income families to vaccinate their pets. Thirteen veterinarians participated, vaccinating a total of 472 pets ( 321 dogs and 151 cats). Of these, 169 (36\%) pets had had no previous vaccination history. Hamilton Public Health Services continues to work with Community Veterinary Outreach, 
which provides pet care for people facing financial pressures, to offer rabies vaccination at a lower cost so pets and people are protected from rabies.

\section{Public health response}

\section{Education and awareness}

The Hamilton Public Health Services developed the "Rabies is Real" public awareness campaign, requesting people to stay away from wild animals; report dead or strangely behaving animals to local animal services; contact public health if they are bitten or scratched by an animal; and to get their pets vaccinated. Campaign materials included billboard posters, colouring booklets for children, social media messaging, newspaper articles, television interviews, a rabies awareness video, and in-person information sessions for high-risk groups (e.g., animal welfare groups). Billboard viewership estimates were provided by the billboard owners and social media views were calculated by the communication team.

The "Rabies is Real" campaign was launched in September 2016. Seventeen billboards at multiple locations across Hamilton were estimated to have been viewed over 8 million times during a 12week period. Campaign banners at 46 different transit shelters were estimated to have had over 13 million views over an 8-week period. The City of Hamilton rabies webpage had 7,393 unique visitors between October 2016 and May 2017, with users spending an average of 3.6 minutes on the webpage and $83 \%$ leaving without going elsewhere on the website.

\section{Rabies Postexposure Prophylaxis (rPEP)}

Hamilton Public Health Services sent out medical advisories informing primary care providers about the raccoon rabies epidemic and the criteria for rPEP and created an educational video on rPEP administration. Compared to 2015, there was a $52 \%$ increase in the number of people who received rPEP in and around Hamilton in 2016 (Figure 2).

Figure 2: Number of clients received rPEP in Hamilton Region in 2015 and 2016

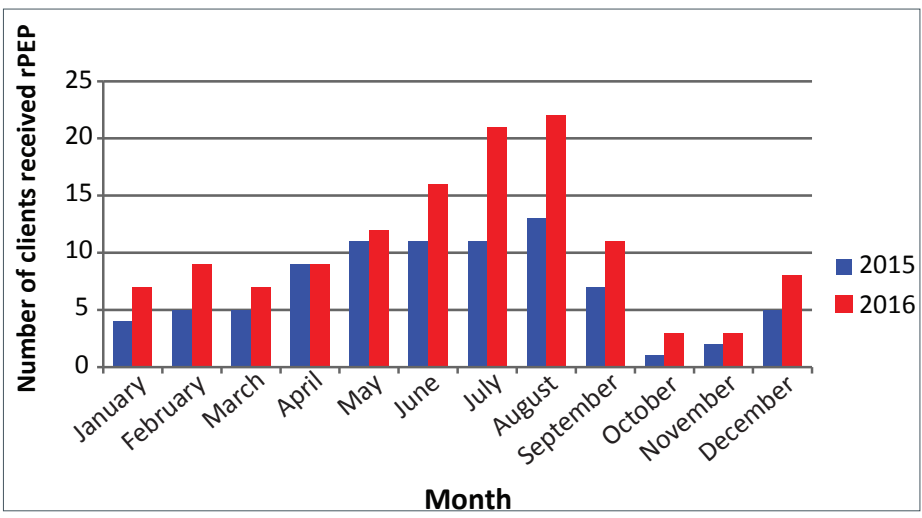

Abbreviation: rPEP, rabies postexposure prophylaxis

The One Health approach to the raccoon rabies outbreak in Ontario is summarized in Table 3.
Table 3: Summary of the One Health approach to the raccoon rabies outbreak, Ontario 2015-2017

\begin{tabular}{|c|c|c|c|c|}
\hline Level & $\begin{array}{l}\text { Government } \\
\text { body or } \\
\text { group }\end{array}$ & $\begin{array}{l}\text { Human } \\
\text { health }\end{array}$ & $\begin{array}{l}\text { Animal } \\
\text { health } \\
\text { (pets and } \\
\text { livestock) }\end{array}$ & $\begin{array}{c}\text { Environment } \\
\text { (wild } \\
\text { animals) }\end{array}$ \\
\hline Federal & CFIA & \multicolumn{3}{|c|}{ Rabies laboratory testing and virus typing } \\
\hline \multirow{3}{*}{ Provincial } & MOHLTC & $\begin{array}{l}\text { Overall } \\
\text { guidance for } \\
\text { local public } \\
\text { health units: } \\
\text { Rabies case } \\
\text { management } \\
\text { protocol } \\
\text { Rabies } \\
\text { immunization } \\
\text { guidelines } \\
\text { (pre and } \\
\text { postexposure) }\end{array}$ & NA & NA \\
\hline & OMAFRA & NA & $\begin{array}{l}\text { Assistance to } \\
\text { veterinarians } \\
\text { regarding risk } \\
\text { assessment, } \\
\text { sample } \\
\text { submission, } \\
\text { postexposure } \\
\text { management }\end{array}$ & NA \\
\hline & MNRF & NA & NA & $\begin{array}{l}\text { Enhanced } \\
\text { rabies } \\
\text { surveillance } \\
\text { including dRIT } \\
\text { testing } \\
\text { Distribution } \\
\text { of } 1.7 \text { million } \\
\text { rabies oral } \\
\text { vaccine baits }\end{array}$ \\
\hline \multirow[t]{3}{*}{ Local } & $\begin{array}{l}\text { Public health } \\
\text { units }\end{array}$ & $\begin{array}{l}\text { Notification } \\
\text { to primary } \\
\text { care providers } \\
\text { and revised } \\
\text { rabies risk } \\
\text { assessment } \\
\text { tool } \\
\text { Postexposure } \\
\text { case } \\
\text { management } \\
\text { including } \\
\text { provision } \\
\text { of rPEP as } \\
\text { needed } \\
\text { Launched } \\
\text { a public } \\
\text { awareness } \\
\text { campaign }\end{array}$ & $\begin{array}{l}\text { Notification } \\
\text { to veterinary } \\
\text { professionals } \\
\text { and animal } \\
\text { services } \\
\text { personnel } \\
\text { Co-organized } \\
\text { rabies vaccine } \\
\text { clinics with } \\
\text { veterinary } \\
\text { physicians }\end{array}$ & NA \\
\hline & $\begin{array}{l}\text { Primary care } \\
\text { providers and } \\
\text { veterinarians }\end{array}$ & $\begin{array}{l}\text { Clinical } \\
\text { management } \\
\text { of potentially } \\
\text { exposed } \\
\text { cases and } \\
\text { administration } \\
\text { of rPEP }\end{array}$ & $\begin{array}{l}\text { Clinical } \\
\text { management } \\
\text { of potentially } \\
\text { exposed } \\
\text { cases and } \\
\text { administration } \\
\text { of rabies } \\
\text { vaccine }\end{array}$ & NA \\
\hline & $\begin{array}{l}\text { Animal control } \\
\text { services }\end{array}$ & NA & \multicolumn{2}{|c|}{$\begin{array}{l}\text { Retrieval and preservation of } \\
\text { dead animals for further testing } \\
\text { or disposition }\end{array}$} \\
\hline
\end{tabular}

Abbreviations: CFIA: Canadian Food Inspection Agency; dRIT, direct rapid immunohistochemical test; MOHLTC, Ministry of Health and Long-Term Care; MNRF, Ministry of Natural Resources and Forestry; NA, not applicable; OMAFRA, Ontario Ministry of Agriculture Food and Rural Affairs; rPEP, rabies postexposure prophylaxis

\section{Discussion}

At the time of this publication, Hamilton Region and surrounding area continue to experience an epizootic of raccoon rabies. The outbreak of raccoon rabies in southwestern Ontario is by far the 
largest to have occurred in Canada. It also differs from previous outbreaks in Ontario, Quebec and New Brunswick in that it is centred in a densely populated urban area. This poses many challenges with respect to control. For example, distribution of baits by low-flying fixed-wing aircraft, as is standard for oral vaccination campaigns in rural areas, is not possible in urban areas. This outbreak required a combination of oral rabies vaccine delivery approaches, such as distribution of baits by hand in the urban centres and by helicopter in large urban green spaces. Bait distribution in the urban core required coordinated messaging from Hamilton Public Health Services, MNRF and OMAFRA to advise the public who came across or into contact with these baits.

A further complication of this urban rabies outbreak lies in the large populations of potential spillover hosts, such as dogs and cats, further raising concern for an increased risk of transmission to humans. Indeed, although the majority of cases have been in wildlife, this is the first time that the raccoon rabies virus variant was identified in domestic animal species in Canada. In the US, the domestic animal species most commonly reported with rabies is the cat, with the majority from areas endemic for raccoon rabies (11). As the outbreak progresses, there is a risk that more cases of raccoon rabies in domestic animal species could occur. As such, key public health messages include encouraging vaccination of all dogs and cats and avoidance of contact with stray animals that are unlikely to be vaccinated. This is challenging given many people choose not to vaccinate their pets despite the legal requirement in Ontario.

Surveillance for rabies in Canada is based on a passive model whereby only suspect animals that have potentially exposed people or domestic animals are tested for rabies. Since the detection of the outbreak in December 2015, the vast majority of cases (>96\%) were detected through the enhanced rabies surveillance program implemented by MNRF. Such surveillance helps delineate the extent of the outbreak, which informs management decisions regarding oral vaccination zones as well as public health risk determinations. These data also speak to the utility of going beyond a passive surveillance model to include the testing of animals found dead or exhibiting clinical signs consistent with rabies, regardless of the history of exposure to humans or domestic animals. Such actions may contribute to earlier detection of new rabies incursions. However, the cost of such a program particularly in the absence of evidence of a disease incursion is a critical consideration. It is important to find a balance between the risk of an incursion going undetected for a period of time and the cost of enhanced surveillance programs.

Introduction of raccoon rabies into Canada in the past has typically resulted from cross-border spread and thus the viral variants on either side of the US-Canada border were very similar. However, genetic analysis of the virus circulating in Hamilton demonstrated that a simple cross-border spread was not the source of this outbreak. It appears that the disease was introduced after a long-distance translocation of a diseased raccoon either by water (shipping) or by land (transport trucking), which has been previously described (12). Thus, even jurisdictions deemed at low risk of a rabies incursion should have contingency plans in place for such an event. The prior existence of contingency plans at MOHLTC (human health response) and MNRF (wildlife rabies control) as well as the existence of the community One Health committee in Hamilton, were key to the speed with which response measures involving diverse programmatic activities were put in place.

Previous raccoon rabies epizootics were eliminated from the provinces of Ontario, Quebec and New Brunswick in six, four and three years, respectively. Given the size of the current epizootic, and the unique challenges of dealing with an urban outbreak, it is not surprising that the outbreak has extended beyond 19 months. However, the decrease in the monthly number of cases and in the percentage of animals testing positive suggests that the epizootic may be decreasing in intensity. The collaborative approach between the various interdisciplinary agencies at the federal (CFIA), provincial (MOHLTC, OMAFRA and MNRF) and local levels (public health units, local animal control and private veterinary professionals) has been instrumental in addressing this raccoon rabies epizootic. Continued collaboration is necessary to again eliminate raccoon rabies from Ontario.

\section{Authors' statement}

DL - Conceptualization, Formal analysis, Writing-Original draft, Writing-Review and editing, Visualization

CDB - Writing-Review and editing, Investigation

CFG - Writing-Review and editing, Investigation

SAND - Writing-Review and editing, Investigation

MECA - Writing-Review and editing

TB - Writing-Review and editing, Formal analysis, Investigation

$\mathrm{KM}$ - Writing-Review and editing, Investigation

CF - Writing-Review and editing

$\mathrm{JH}$ - Conceptualization, Writing-Review and editing,

Investigation, Supervision

\section{Conflict of Interest}

None.

\section{Funding}

None.

\section{Acknowledgements}

We thank all the staff at Hamilton Public Health Services, MOHLTC, OMAFRA, MNRF Wildlife Research and Monitoring Section and the CFIA Rabies Laboratory in Ottawa who contributed to the rabies response activities.

\section{References}

1. Wunner WH, Conzelmann KK. Chapter 2: Rabies virus. In: Jackson AC, editor. Rabies - Scientific basis of the disease and its management. 3rd ed. San Diego: Elsevier Inc; 2013. pp. 17-60.

2. Nadin-Davis SA. Chapter 4: Molecular Epidemiology. In: Jackson AC, editor. Rabies - Scientific basis of the disease and 
its management. 3rd Edition). San Diego: Elsevier Inc; 2013. pp. 123-77.

3. Hanlon CA, Childs JE. Chapter 3: Epidemiology. In: Jackson $A C$, editor. Rabies - Scientific basis of the disease and its management. 3rd ed. San Diego: Elsevier Inc; 2013. pp. 61121.

4. Centers for Disease Control and Prevention (CDC). Update: raccoon rabies epizootic--United States and Canada, 1999. MMWR Morb Mortal Wkly Rep 2000 Jan;49(2):31-5. PubMed (https://www.ncbi.nlm.nih.gov/ pubmed/10680602?dopt=Abstract)

5. Wandeler Al, Salsberg EB. ONTARIO. Raccoon rabies in eastern Ontario. Can Vet J 1999 Oct;40(10):731.

PubMed (https://www.ncbi.nlm.nih.gov/ pubmed/17424571?dopt=Abstract)

6. Stevenson B, Goltz J, Massé A. Preparing for and responding to recent incursions of raccoon rabies variant into Canada. Can Commun Dis Rep. 2016;42(6):125-9. http://dx.doi. org/10.14745/ccdr.v42i06a03

7. One Health Global Network. What is One Health? http://www. onehealthglobal.net/what-is-one-health/

8. Middel K, Fehlner-Gardiner C, Pulham N, Buchanan T Incorporating direct rapid immunohistochemical testing into large-scale wildlife rabies surveillance. TropicalMed 2017;2(3):21. http://dx.doi.org/10.3390/tropicalmed2030021
9. Canadian Food Inspection Agency. Rabies in Canada 2014 [cited 2017 Oct 14]. http://www.inspection.gc.ca/animals/ terrestrial-animals/diseases/reportable/rabies/rabies-incanada-2014/eng/1424879193262/1424879195231

10. Trewby H, Nadin-Davis SA, Real LA, Biek R. Processes underlying rabies virus incursions across US-Canada border as revealed by whole-genome phylogeography. Emerg Infect Dis 2017 Sep;23(9):1454-61. http://dx.doi.org/10.3201/ eid2309.170325. PubMed (https://www.ncbi.nlm.nih.gov/ pubmed/28820138?dopt=Abstract)

11. Birhane MG, Cleaton JM, Monroe BP, Wadhwa A, Orciari LA, Yager P, Blanton J, Velasco-Villa A, Petersen BW, Wallace RM. Rabies surveillance in the United States during 2015. J Am Vet Med Assoc 2017 May;250(10):1117-30. http://dx.doi. org/10.2460/javma.250.10.1117. PubMed (https://www.ncbi. nlm.nih.gov/pubmed/28467751?dopt=Abstract)

12. Smith DL, Waller LA, Russell CA, Childs JE, Real LA. Assessing the role of long-distance translocation and spatial heterogeneity in the raccoon rabies epidemic in Connecticut. Prev Vet Med 2005 Oct;71(3-4):225-40. http://dx.doi. org/10.1016/j.prevetmed.2005.07.009. PubMed (https://www. ncbi.nlm.nih.gov/pubmed/16153724?dopt=Abstract)

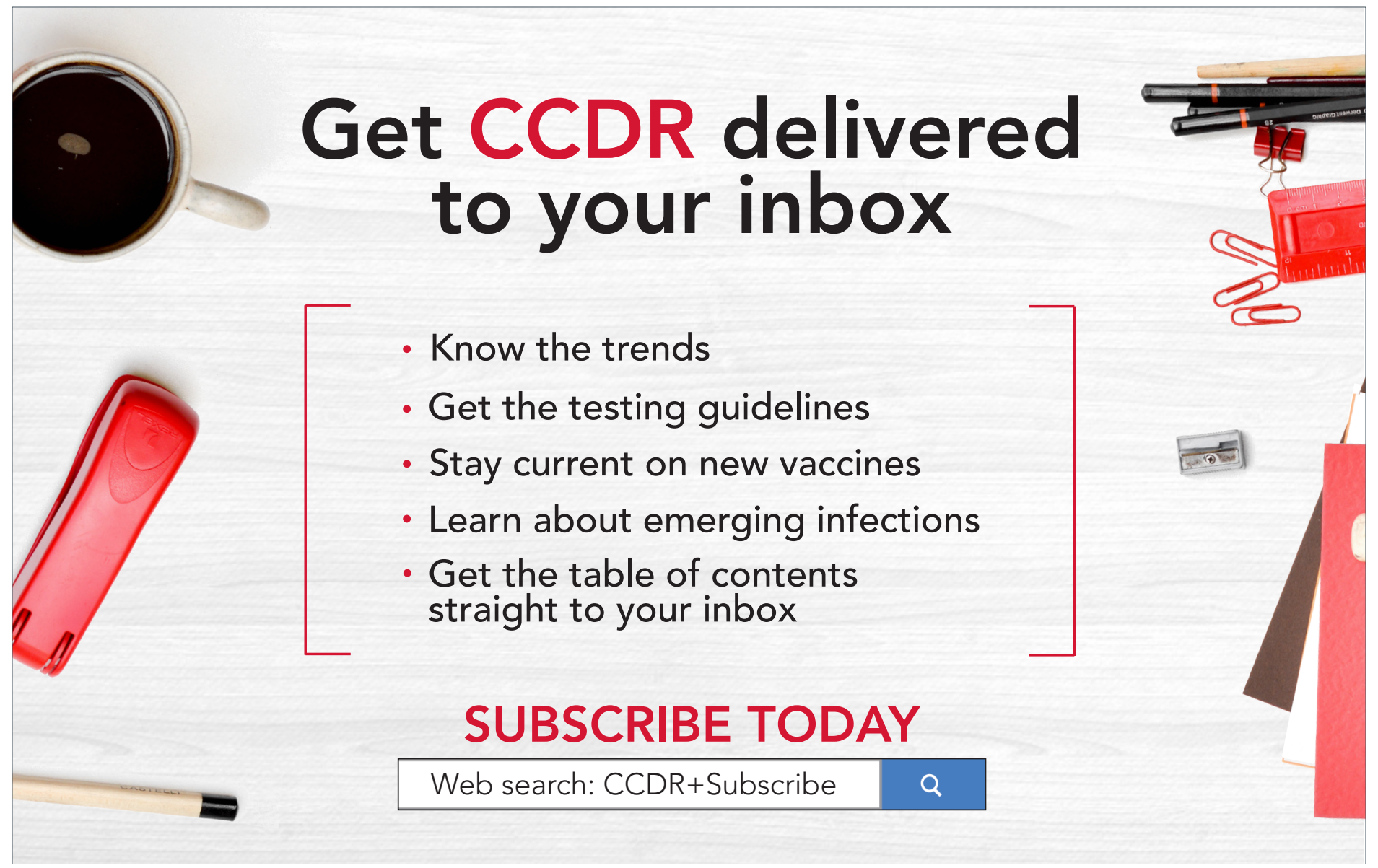

